\title{
Depression Levels Following Discharge Predict Quality of Life in Heart Disease Patients
}

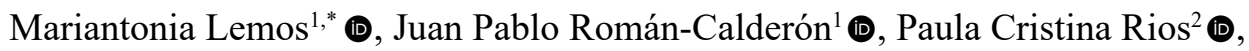 \\ Susana Torres ${ }^{1}$ (D), Diana María Agudelo ${ }^{3}$ (1) \\ ${ }^{1}$ Universidad EAFIT, Medellín, Colômbia \\ ${ }^{2}$ Universidad Católica de Oriente, Rionegro, Colômbia \\ ${ }^{3}$ Universidad de Los Andes, Bogotá, Colômbia
}

\begin{abstract}
Depression and stress have been related with poor Health Related Quality of Life (HRQoL) prognosis. However, it is not clear when these depressive symptoms should be measured. A sample of 177 Coronary Heart Disease patients were followed for 15 months aimed to compare the effect of depression and stress measure at time of hospitalization and three months later on the physical HRQoL trajectory. Linear growth models' results showed that depression and stress after discharge are negatively correlated with the physical HRQoL and depressive symptoms negatively affect the prognosis of these patients.
\end{abstract}

KEYWORDS: depression, stress, quality of life, heart disease, linear growth models

\section{Depressão após Alta Prediz Qualidade de Vida Prévia em Pacientes Cardíacos}

\begin{abstract}
RESUMO - Depressão e estresse têm sido associados ao prognóstico da Qualidade de Vida Relacionada à Saúde (QVRS). Contudo, não há clareza sobre quando os sintomas de depressão devem ser mensurados. Uma amostra de 177 pacientes com cardiopatia isquêmica foi acompanhada por 15 meses, para comparar o efeito do estresse e a depressão durante a internação e, três meses depois, avaliou-se a trajetória do componente físico da QVRS. Os resultados da comparação de duas curvas de crescimento latente mostraram que a depressão e o estresse pós-alta estão negativamente correlacionados com o componente físico da QVRS, e que os sintomas depressivos afetam negativamente o prognóstico desses pacientes.
\end{abstract}

PALAVRAS-CHAVE: depressão, estresse, qualidade de vida, cardiopatia isquêmica, curvas de crescimento latente

Coronary Heart Disease (CHD) is a common cause of death and disability worldwide (Puddu, Piras, \& Menotti, 2017; Wang, Dixson, Schiller, \& Whooley, 2017). This disease represents an important proportion of deaths before the age of 70 years (Khan, Kella Kunutsor, Savonnen, \& Laukkanen, 2018). Over three quarters of these deaths occur in low- and middle-income countries (World Health Organization, 2014). Furthermore, CHD is one of the five leading contributors of disability in elderly people in these countries (Mendis, Puska, \& Norrving 2011). Thus, the burden caused by CHD is not only due of the mortality but also of nonfatal cardiac events and their consequences (Dahlöf, 2010; Heidenreich et al., 2011).

Depression and stress are common in CHD patients (Gorayeb, Bovo, de Lima, Magaldi, Tamie \& Schmidt, 2015; Palacios, Khondoker, Tylee \& Hotopf, 2018). Depression is highly prevalent ( Abbasi et al., 2018; Almeida, Alfonso, Flicker, Hankey, \& Norman, 2011). A systematic review of the literature found that approximately $20 \%$ of patients with an Acute Myocardial Infarction (AMI) fulfilled the criteria for major depression and another $31 \%$ reported some depressive symptoms (Thombs et al., 2006). Regarding

*E-mail: mlemosh@eafit.edu.co

- Submetido: 23/01/2017; Revisado: 05/09/2018; Aceito: 03/12/2019. 
stress in CHD, is has been recognized that patients report more stress levels than controls (Lanas et al., 2007; Rosengren et al., 2004).

These two psychological factors have been related to poor prognosis (Iles-Smith, McGowan, Campbell, Mercer, \& Deaton, 2014; Rosengren et al., 2004). Researchers have shown that depression is related with morbidity and mortality after an acute cardiac syndrome (Carney et al., 2008; Davidson et al., 2010; Lichtman et al., 2014; Nabi et al., 2010); and also with poor Health Related Quality of Life (HRQoL) (de Jonge, Spijkerman, van den Brink, \& Ormel, 2006; Lane, Carroll, Ring, Beevers, \& Lip, 2001; Ruo et al., 2003; Wang, Jiang, \& Lee, 2016), which has been recognized as a relevant parameter to measure the prognosis and success of interventions on CHD patients (Ladwig et al., 2014). This relation was found in a systematic review of 11 studies that showed that depression predicted subsequent physical HRQoL, independently of confounding factors such as the severity of CHD and baseline HRQoL (Dickens, Cherrington, \& McGowan, 2012).

Conversely, other studies have found that depressive symptoms in the moment of the hospitalization due to the acute cardiac syndrome are not related with worse prognosis (Dickens et al., 2007; Lane et al., 2001; Parakh, Thombs, Fauerbach, Bush, \& Ziegelstein, 2008). This could be related to the different trajectories that depressive symptoms can take in CHD patients (Kaptein, de Jonge, van den Brink, \& Korf, 2006). Depressive symptoms at the moment of hospitalization could be explained by the event and be transient for some patients, while others might have persistent symptoms (Thombs et al., 2008).

Hence, it is plausible to think that the relationship between depression and poor prognosis in CHD patients is related to the time frame when the depressive symptoms appeared and their duration. In this vein, it has been suggested that the main action of depression on worse prognosis in CHD patients occurs after the cardiac event takes place (Carney \& Freedland, 2012b; de Jonge, Spijkerman, et al., 2006). Furthermore, some researchers have conveyed that resistant depression was associated with high risk of mortality in this population (Carney \& Freedland, 2009; Scherrer et al., 2012). Finally, persistent depressive symptoms or new depressive symptoms after the discharge have been found to be associated with poor prognosis in the physical HRQoL one year later (Thombs et al., 2008).

Given this evidence and the fact that it has been recommended to assess depressive symptoms in $\mathrm{CDH}$ patients (Lichtman et al., 2008), it is necessary to know when is the appropriate time to do this in order to implement an intervention. Thus, the present longitudinal study aimed to compare the effect of depression and stress measure at time of hospitalization and three months later on the physical HRQoL trajectory in CHD patients followed for 15 months in Colombia.

\section{METHOD}

\section{Design and Patients}

Overall, 190 patients with a documented CHD voluntarily participated in the study. Patients were invited to participate while they were hospitalized for an acute cardiac syndrome. The patients were followed up for 15 months. Trained staff administered the questionnaires every 3 months. At the end of the study, data retrieved in 6 measurements and from 177 participants was suitable for the analyses. $67 \%$ of the participants were men, and the average age was 64 years ( $S D$ $=11.27)$. The majority of the participants were married or had a long-term partner (62.6\%). 38.4\% of the patients had a low socio-economic position and $48.6 \%$ were employed. Concerning their clinical characteristics, $42.6 \%$ had had a Myocardial Infarction, $20.0 \%$ of the sample fulfilled the criteria for a depression disorder at time point 0 , and $7.4 \%$ fulfilled these criteria three months after discharge.

\section{Measures}

In order to assess depression, we used a composite measure drawn from the Patient Health Questionnaire depression module (PHQ-9) (Kroenke \& Spitzer, 2002). The PHQ- 9 is composed by 9 items and is suitable to assess depression and its severity (Spitzer, Kroenke, \& Williams, 1999). Respondents score in a 4 point Likert scale that goes from 1-absence to 3-every day. A total score less than 8 in this module suggests absence of depression; scores from 8 to 9 indicate possible depression: scores of 10 or above strongly suggest depression (Kroenke \& Spitzer, 2002). In this study, Cronbach's alphas were .73 for time 0 (hospitalization) and .82 for time 1 (three months after discharge).

Perceived stress was assessed using the Perceived Stress Questionnaire (PSS) (Cohen, Kamarck, \& Mermelstein, 1983). The PSS has 14 items and respondents score on a five-point Likert scale that ranges from 0 (never) to 4 (almost always). The Spanish version of the PSS-14 showed good reliability, Cronbach's $\alpha=.81$; test-retest $r=.73$ (Remor, 2006). Similarly, the Colombian version of the PSS obtained a good reliability coefficient (Cronbach's $\alpha=.86$ ) (CampoArias, Bustos-Leiton, \& Romero-Chaparro, 2009). The PSS obtained good reliability in time 0 and time 1 , Cronbach's $\alpha=.82$ and .84 respectively.

Finally, Physical component of HRQoL was measured with the relevant composite sub-scale of the 36 item Short Form (SF-36). This instrument was developed for the Medical Outcome Study in order to assess quality of life with a generic and easily administered measure. The SF- 36 has demonstrated 
good reliability (Vilagut et al., 2005) and has been validated for CHD patients (Nascimento, Alves, Pio, \& Carisi, 2009). The Colombian version has satisfactory psychometric properties (Lugo, Garcia, \& Gomez, 2006). In a study with post-CHD Colombian patients, the subscales of the physical health component of the SF-36 showed good reliability (Cronbach's $\alpha$ between 0.90 and 0.74) (Romero, 2010). This component obtained good reliability for all the time measures in the current sample, Cronbach's alpha of .92 for time $0, .93$ for time $1, .95$ for time 2 ( 6 months after discharge), .96 for time 3 (9 months after discharge), time 4 (12 months after discharge) and time 5 (15 months after discharge).

\section{Statistical Analyses}

Mplus (v. 6.12; Muthén \& Muthén, 2010) was used to conduct the statistical analyses. The Growth Modeling approach was adopted to test the effects of depression and stress on the physical HRQoL trajectory in CHD patients. Two linear growth models (LGMs) were tested in which the change of Physical component of HRQoL over a 15-month period was predicted by depression and stress levels. The two LGMs were specified as follows: in the first model (LGM1) depression and stress at time 0 (hospitalization) $\left(t_{0}\right)$ were constrained to predict the intercept and slope of Physical component of HRQoL over the following 15 months. In the second model (LGM2) depression and stress at time 1 (3 months after discharge) $\left(t_{1}\right)$ were constrained to predict the intercept and slope of Physical component of HRQoL over the following 12 months. Model fit was assessed using the $\chi^{2}$ df ratio test, the Root Mean Square Error of Approximation (RMSEA) and Tucker Lewis Index (TLI). Critical values for these coefficients are: $\chi^{2} / \mathrm{df}$ ratio below 2 suggest good model fit (Byrne, 1989). For RMSEA, values of $<.70$ are acceptable (Hu \& Bentler, 1999). For TLI, values of $>.90$ are considered satisfactory and $>.95$ are desirable (Bentler, 1990). Further, 95\% confidence intervals were calculated for all the regression paths composing the LGMs. Finally, having in mind that older age and being male have been related with higher risk of a cardiac event and poor HRQOL (American Heart Association, 2010), age and sex were introduced as controls in the selected LGM.

\section{RESULTS}

Skewness and kurtosis coefficients for all variables were below the cut-off values (between 2 and -2; Bandalos \& Finney, 2010; Muthén \& Kaplan, 1985a, 1985b). This allowed the use of the ML estimator. Means of Physical component of HRQoL varied across all time points $\left(t_{0}=49.51 ; t_{1}=48.84 ; t_{2}=57.59 ; t_{3}=61 ; t_{4}=59.75\right)$. Stress and depression were positively correlated at $t_{0}\left(r_{\mathrm{s}}=.56, p\right.$ $<.01,95 \%$ CI $[.42, .67])$, and $t_{1}\left(r_{\mathrm{s}}=.54, p<.01,95 \% \mathrm{CI}\right.$ $[.34, .69])$. Correlations between stress and depression with HRQOL are displayed in Table 1.
The coefficients of LGM1, where depression at $t_{0}$ (hospitalization) predicted the slope of the Physical component of HRQoL from that time point, indicated that the model had a poor fit to the data $\left(\chi^{2}(23,177)=251.07, p\right.$ $<.001$; RMSEA = .23; TLI = .54). Conversely, all goodness of fit coefficients for the LGM2 resulted satisfactory $\left(\chi^{2}(15\right.$, $177)=26.40, p=.03$; RMSEA $=.065 ;$ TLI $=.91)$. Thus, LGM2 was accepted over LGM1, as shown in Table 2.

The LGM2 (see figure 1) suggests that levels of depression $(r=-.38, p<.01,95 \%$ CI [-.55, -.22]) and stress

Table 1

Correlations between stress, depression and Health Related Quality of Life (HRQOL)

\begin{tabular}{lccccc}
\hline & HRQOL Time 1 & HRQOL Time 2 & HRQOL Time 3 & HRQOL Time 4 & Depression Time 1 \\
\hline HRQOL Time 2 & .35 & & & & \\
HRQOL Time 3 & .38 & .79 & .69 & & \\
HRQOL Time 4 & .33 & .54 & -.65 & -.64 & \\
Depression Time 1 & -.32 & -.52 & -.42 & -.46 & -.55 \\
Stress Time 1 & -.26 & -.42 & & & \\
\hline
\end{tabular}

Table 2

Linear Growth Models goodness of fit indexes

\begin{tabular}{lccccc}
\hline Model & $\chi^{2}$ & Df & p value & RMSEA & TLI \\
\hline LGM1: $t_{0}$ to $t_{4}$ & 251.07 & 23 & .001 & .23 & .54 \\
LGM2: $t_{1}$ to $t_{4}$ & 26.40 & 15 & .03 & .065 & .91 \\
\hline
\end{tabular}

$\mathrm{N}=177 ;$ ML estimator 
$(r=-.37, p<.01,95 \%$ CI $[-.56,-.17])$ three months after discharge were negatively and significantly correlated with the Physical component of HRQoL at this time point $\left(t_{1}\right)$. Furthermore, depressive symptoms negatively affected the slope of the Physical component of HRQoL from $t_{1}$ to $t_{4}(B$ $=-.74, p<.05,95 \% \mathrm{CI}[-1.25,-.22])$. In addition, the results suggest that stress at $t_{1}$ (three months after discharge), in contrast to depression, did not have a statistically significant influence on the growth curve of Physical component of HRQoL ( $(=-0.12$, n.s, 95\% CI [-.53, .29]). Finally, age and sex were introduced in the LGM2 as covariates of the slope and intercept of HRQoL. As a result, the negative effect of depression on the growth curve of Physical component of HRQoL continued to be statistically significant, and being men was found to have a positive effect and statistically significant relationship with psychical HRQoL (Figure 1).

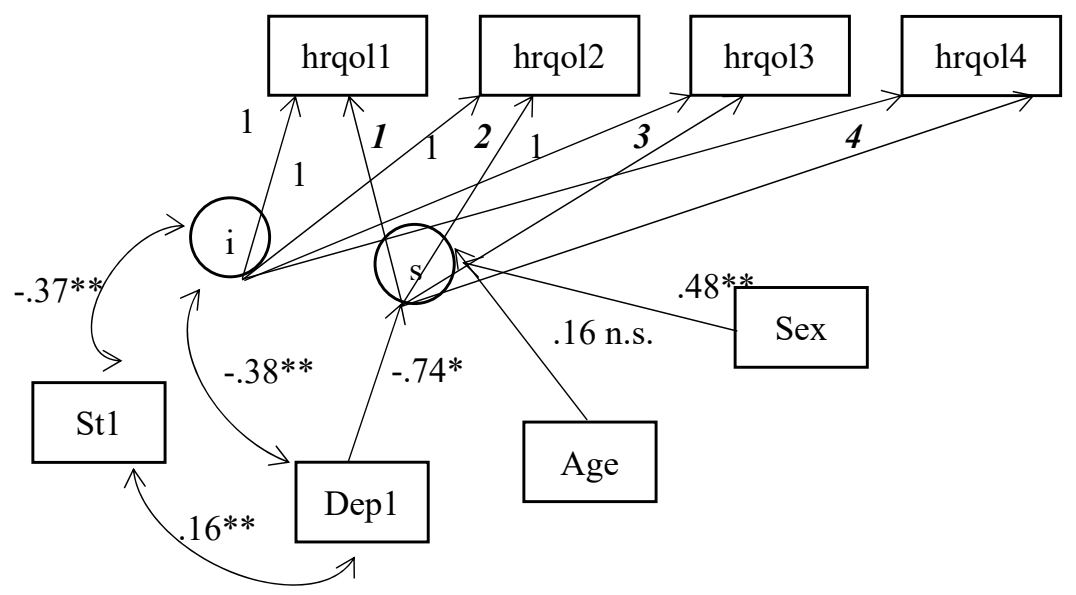

Figure 1. Linear Growth Model (LGM2) results and specification (standardized).

Note: $\mathrm{n}=177 ; i=$ intercept of physical quality of life; $s=$ slope of physical quality of life; Dep1 = depression three months after hospitalization; St 1 = stress three months after hospitalization; hrqol from 1 to 4, physical quality of life measured every three months after hospitalization. Paths from the $i$ to each hrqol measurement fixed at 1 as default in linear growth models. Paths from s to hrqol measurements were numbered from 1 to 4 to specify a linear growth model with equidistant time points. * significant at the $p<.05$ level; ** significant at the $p<.01$.

\section{DISCUSSION}

The purpose of this study was to compare the effects of depression and stress measures at time of hospitalization and three months after discharge on the physical HRQoL trajectory in CHD patients. Stress and depression were correlated with the Physical component of HRQoL. Additionally, the results suggest that depressive symptoms measured three months after discharge were negatively related with physical HRQoL prognosis over the 15 months after hospitalization.

Cardiac hospitalization events are stressful life events that can negatively affect patients' HRQoL (Allam, Nabih, \& El-Missiry, 2018; Borowiak \& Kostka, 2006; White \& Groh, 2007). Patients' knowledge about their disease can affect their mental health and exacerbate depressive and anxious symptoms (Carney \& Freedland, 2012a; Holahan, Moerkbak, \& Suzuki, 2006). It has shown that the effects of these symptoms are not limited to the time frame when the cardiac event occurred, and their consequences go beyond the mental component (Dickens et al., 2006; Worcester et al., 2007); however, this study provides new evidence about the relation between stress, depression and the Physical HRQoL, measuring depressive symptoms three months after discharge.
The prevalence of depression in our sample at time of hospitalization is similar to that reported in other studies (Doyle et al., 2015; Thombs et al., 2006). However, only $38 \%$ of those who were depressed at the baseline remained depressed three months later. Our results suggest that not all CHD patients who have depressive symptoms concurrent to the cardiac event have a worse prognosis compared to patients without depression. Depressive symptoms comorbid with the cardiac event could be transient and might be conceptualized as part of an adjustment syndrome (Ski, Worrall-Carter, et al., 2015). Additionally, in these patients the hospitalization process could be a reason for being depressed (Navarro-García et al., 2011). This might help to explain the negative results that have been shown by some studies that have not found a relation between depression and HRQoL (Almeida et al., 2011; Dickens et al., 2007; Parakh et al., 2008).

Trajectories of depressive symptoms in CHD patients seem to be heterogeneous (Kaptein et al., 2006; Thombs et al., 2008). Only those patients with persistent symptoms or those with new depressive symptoms that appear after the event seem to have worse prognosis after a CHD event (de Jonge, van den Brink, Spijkerman, \& Ormel, 2006; Kaptein 
et al., 2006; Parker et al., 2008). This association could be related to reports of poor adherence to medical regimen and cardiac rehabilitation attendance in depressive CHD patients (Casey, Hughes, Waechter, Josephson, \& Rosneck, 2008; Glazer, Emery, Frid, \& Banyasz, 2002; Ziegelstein et al., 2000). Thus, measuring depressive symptoms three months after the event could be a better way to identify those patients with higher risk in order to give them professional attention. Similarly, another study indicates the importance of addressing depressive symptoms in the development of interventions that target HRQoL (Lee, Lennie, Wu, Biddle, \& Moser, 2014; Ski, Jelinek, Jackson, Murphy, \& Thompson, 2015)

Depression and stress have been associated with biological and behavioral CHD risk factors (Araujo-Moxoto \& Novaes-Malagris, 2015; Everson \& Lewis, 2005; Lichtman et al., 2008). These relationships have been found to be significant also in CHD patients (Lichtman et al., 2014). Reduced heart rate variability, HPA axis dysfunction, increased CRP, IL-6, and fibrinogen levels are some of the mechanism that relate stress and depression with CHD (Carney et al., 2007; Dowlati et al., 2010; Kendall-Tackett, 2009; Merz et al., 2002). These patients also are less likely to modify unhealthy habits like smoking, sedentary life style, high saturated fat food intake (Dickens et al., 2012; Everson \& Lewis, 2005; Jacka et al., 2007). In stress specifically, a number of observational studies have reported an association between mental stress and adverse cardiac events or total mortality (Wei et al., 2014)2014.

According to our findings, stress three months after discharge is negatively and significantly correlated with the
Physical component of HRQoL at this time point. These results are similar to those of previous studies showing that, after adjustment for demographic and clinical factors as well as depression, high stress was associated with a threefold increased risk of 30-day readmission $(\mathrm{HR}=3.21,95 \% \mathrm{CI}=$ 1.13, 9.10) (Edmondson, Green, Ye, Halazun, \& Davidson, 2014). A possible explanation for the not statistically significant influence of stress at time point 1 on the slope of the growth curve of Physical component of HRQoL could be that it is mediated by high levels of social support (LeónPérez, Wallston, Goggins, Poppendeck, \& Kripalani, 2016; Volz et al., 2011). In our study, although this condition is not measured specifically, a proxy for this could be a marital status, so, in our sample, the majority of the participants $(62.6 \%)$ were married or with a long-term partner.

The present study has some limitations that are important to consider. First, somatic symptoms of depression could be confounded with the physical HRQoL level. However, researchers have considered that measuring these symptoms is important in the diagnosis of depression, and that ignoring them could lead to biased results (Carney \& Freedland, 2012a). Second, the study did not control for other conditions that could affect the physical HRQoL trajectory. Future studies should assess for the presence of other conditions to control for them. Finally, there remain important, unanswered questions about whether treating depression after CHD and other mental health conditions not only improves patient symptoms but also reduces subsequent mortality risk, and about the psychosocial and physiological mechanisms involved in such treatment (Williams, Ghose, \& Swindle, 2014).

\section{REFERENCES}

Abbasi, M., Neishaboury, M., Koohpayehzadeh, J., Etemad, K., Meysamie, A... Esteghamati, A. (2018). National Prevalence of Self-Reported Coronary Heart Disease and Chronic Stable Angina Pectoris: Factor Analysis of the Underlying Cardiometabolic Risk Factors in the SuRFNCD-2011. Global Heart, 13(2), 73-82. https://doi.org/10.1016/j. gheart.2018.01.001

Allam, L.E., Nabih, M. A., \& El-Missiry, M. A. (in press). The psychological impact of permanent cardiac pacemakers on pediatric patients and their parents: A case control study. Indian Heart Journal. https://doi.org/10.1016/j.ihj.2018.02.007

Almeida, O. P., Alfonso, H., Flicker, L., Hankey, G. J., \& Norman, P. E. (2011). Cardiovascular Disease, depression and mortality: The Health In Men Study. American Journal of Geriatric Psych, 20(5), 433-440. https://doi.org/10.1097/ JGP.0b013e318211c1ed

American-Heart-Association. (2010). Risk factors and Coronary Artery Disease. Retrieved from http://www.americanheart. $\mathrm{org} /$ presenter.jhtml?identifier $=4726$

Araujo-Moxoto, G.de F., \& Novaes-Malagris, L.E. (2015). Raiva, stress emocional e hipertensao: Um estudo comparativo. Psicologia: Teoria e Pesquisa, 31(2), 221-227. https://doi. org/10.1590/0102-37722015021189221227
Bentler, P. M. (1990). Comparative fit indexes in structural models. Psychological Bulletin, 107(2), 238-246. https://doi. org/10.1037/0033-2909.107.2.238

Bandalos, D. L., \& Finney, S. J. (2010). Factor Analysis: Exploratory and confirmatory. In G. R. Hancock \& R. O. Mueller (Eds.), Reviewer's guide to quantitative methods. New York, NY: Routledge.

Borowiak, E., \& Kostka, T. (2006). Influence of chronic cardiovascular disease and hospitalisation due to this disease on quality of life of community-dwelling elderly. Quality of Life Research, 15(7), 1281-1289. https://doi.org/10.1007/ s11136-006-0058-0

Byrne, B. M. (1989). A primer of LISREL: Basic applications and programming for confirmatory factor analytic models. New York: Springer-Verlag.

Campo-Arias, A., Bustos-Leiton, G. J., \& Romero-Chaparro, A. (2009). Consistencia interna y dimensionalidad de la Escala de Estrés Percibido (EEP-10 y EEP-14) en una muestra de universitarias de Bogotá, Colombia. Aquichan, 9(3), 271-280.

Carney, R. M., \& Freedland, K. E. (2009). Treatment-resistant depression and mortality after acute coronary syndrome. The American Journal of Psychiatry, 166(4), 410-417. https://doi. org/10.1176/appi.ajp.2008.08081239 
Carney, R. M., \& Freedland, K. E. (2012a). Are somatic symptoms of depression better predictors of cardiac events than cognitive symptoms in Coronary Heart Disease? Psychosomatic Medicine, 74(1), 33-38. https://doi.org/10.1097/ PSY.0b013e3182405ac4

Carney, R. M., \& Freedland, K. E. (2012b). Is there a high-risk subtype of depression in patients with coronary heart disease? Current Psychiatry Reports, 14(1), 1-7. https://doi.org/10.1007/ s11920-011-0247-6

Carney, R. M., Freedland, K. E., Stein, P. K., Miller, G. E., Steinmeyer, B., Rich, M. W., \& Duntley, S. P. (2007). Heart rate variability and markers of inflammation and coagulation in depressed patients with coronary heart disease. Journal of Psychosomatic Research, 62(4), 463-467. https://doi. org/10.1016/j.jpsychores.2006.12.004

Carney, R. M., Freedland, K. E., Steinmeyer, B. C., Blumenthal, J. A., Berkman, L. F., Watkins, L. L., . . Jaffe, A. S. (2008). Depression and five year survival following acute myocardial infarction: a prospective study. Journal of Affective Disorders, 109(1), 133-138. https://doi.org/10.1016/j.jad.2007.12.005

Casey, E., Hughes, J. W., Waechter, D., Josephson, R., \& Rosneck, J. (2008). Depression predicts failure to complete phase-II cardiac rehabilitation. Journal of Behavioral Medicine, 31(5), 421-431. https://doi.org/10.1001/s10865-008-9168-1

Cohen, S., Kamarck, T., \& Mermelstein, R. (1983). A global measure of perceived stress. Journal of Health and Social Behavior, 24(4), 385-396. https://doi.org/10.1037/t02889-000

Dahlöf, B. (2010). Cardiovascular disease risk factors: Epidemiology and risk assessment. The American Journal of Cardiology 105(1), 3A-9A. https://doi.org/10.1016/j.amjcard.2009.10.007

Davidson, K. W., Burg, M. M., Kronish, I. M., Shimbo, D., Dettenborn, L., Mehran, R., ... Lespérance, F. (2010). Association of anhedonia with recurrent major adverse cardiac events and mortality 1 year after acute coronary syndrome. Archives of General Psychiatry, 67(5), 480 - 488. https://doi. org/10.1001/archgenpsychiatry.2010.36

de Jonge, P., Spijkerman, T. A., van den Brink, R. H. S., \& Ormel, J. (2006). Depression after myocardial infarction is a risk factor for declining health related quality of life and increased disability and cardiac complaints at 12 months. Heart, 92(1), 32-39. https://doi.org/10.1136/hrt.2004.059451

de Jonge, P., van den Brink, R. H. S., Spijkerman, T. A., \& Ormel, J. (2006). Only incident depressive episodes after myocardial infarction are associated with new cardiovascular events. Journal of the American College of Cardiology, 48(11), 22042208. https://doi.org/10.1016/j.jacc.2006.06.077

Dickens, C., Cherrington, A., \& McGowan, L. (2012). Depression and health-related quality of life in people with coronary heart disease: A systematic review. European Journal of Cardiovascular Nursing, 11(3), 265-275. https://doi. org/10.1177/1474515111430928

Dickens, C., McGowan, L., Percival, C., Tomenson, B., Cotter, L., Heagerty, A., \& Creed, F. (2007). Depression is a risk factor for mortality after myocardial infarction: Fact or artifact? Journal of the American College of Cardiology, 49(18), 1834-1840. https://doi.org/10.1016/j.jacc.2007.01.075

Dickens, C., McGowan, L., Percival, C., Tomenson, B., Cotter, L., Heagerty, A., \& Creed, F. H. (2006). Contribution of depression and anxiety to impaired health-related quality of life following first myocardial infarction. The British Journal of Psychiatry, 189(4), 367-372. https://doi.org/10.1192/bjp.bp.105.018234

Dowlati, Y., Herrmann, N., Swardfager, W., Liu, H., Sham, L., Reim, E. K., \& Lanctôt, K. L. (2010). A meta-analysis of cytokines in major depression. Biological Psychiatry, 67(5), 446-457. https://doi.org/10.1016/j.biopsych.2009.09.033

Doyle, F., McGee, H., Conroy, R., Conradi, H. J., Meijer, A., Steeds, R., ... Carney, R. (2015). Systematic review and individual patient data meta-analysis of sex differences in depression and prognosis in persons with myocardial infarction: A
MINDMAPS Study. Psychosomatic Medicine, 77(4), 419-428. https://doi.org/10.1097/PSY.0000000000000174

Edmondson, D., Green, P., Ye, S., Halazun, H. J., \& Davidson, K. W. (2014). Psychological stress and 30-day all-cause hospital readmission in acute coronary syndrome patients: An observational cohort study. PloS one, 9(3), e91477. https://doi. org/10.1371/journal.pone.0091477

Everson, S. A., \& Lewis, T. T. (2005). Psychosocial factors and cardiovascular diseases. Annual Review of Public Health, 26, 469-500. https://doi.org/10.1146/annurev. publhealth.26.021304.144542

Glazer, K. M., Emery, C. F., Frid, D. J., \& Banyasz, R. E. (2002). Psychological predictors of adherence and outcomes among patients in cardiac rehabilitation. Journal of Cardiopulmonary Rehabilitation and Prevention, 22(1), 40-46. https://doi. org/10.1097/00008483-200201000-00006

Gorayeb, R., Bovo, G., de Lima, P., Magaldi, A.L., Tamie, R. \& Schmidt, A. (2015). Efeitos de invervencao cognitivocomportamental sobre fatores de risco psicológicos en cardiopatas. Psicologia: Teoria e Pesquisa, 31(3), 355-363. https://doi.org/10.1590/0102-37722015032103355363

Heidenreich, P. A., Trogdon, J. G., Khavjou, O. A., Butler, J., Dracup, K., Ezekowitz, M. D., ... Khera, A. (2011). Forecasting the future of cardiovascular disease in the United States a policy statement from the American heart association. Circulation, 123(8), 933-944. https://doi.org/10.1161/ CIR.0b013e31820a55f5

Holahan, C. K., Moerkbak, M., \& Suzuki, R. (2006). Social support, coping, and depressive symptoms in cardiac illness among Hispanic and non-Hispanic White cardiac patients. Psychology and Health, 21(5), 615-631. https://doi. org/10.1080/14768320500457168

Hu, L., \& Bentler, P. M. (1999). Cutoff criteria for fit indexes in covariance structure analysis: Conventional criteria versus new alternatives. Structural Equation Modeling: A Multidisciplinary Journal, 6(1), 1-55. https://doi. org/10.1080/10705519909540118

Iles-Smith, H., McGowan, L., Campbell, M., Mercer, C., \& Deaton, C. (2014). A prospective cohort study investigating readmission, symptom attribution and psychological health within six months of primary percutaneous coronary intervention. European Journal of Cardiovascular Nursing, 14(6), 506-517. https://doi.org/10.1177/1474515114543227

Jacka, F. N., Pasco, J. A., McConnell, S., Williams, L. J., Kotowicz, M. A., Nicholson, G. C., \& Berk, M. (2007). Self-reported depression and cardiovascular risk factors in a community sample of women. Psychosomatics, 48(1), 54-59. https://doi. org/10.1176/appi.psy.48.1.54

Khan, H., Kella, D., Kunutsor, S. K., Savonnen, K. \& Laukkanen, J. (in press). Sleep duration and risk of fatal coronary heart disease, sudden cardiac death, cancer death and all-cause mortality. The American Journal of Medicine. https://doi. org/10.1016/j.amjmed.2018.07.010

Kaptein, K. I., de Jonge, P., van den Brink, R. H. S., \& Korf, J. (2006). Course of depressive symptoms after myocardial infarction and cardiac prognosis: a latent class analysis. Psychosomatic Medicine, 68(5), 662-668. https://doi. org/10.1097/01.psy.0000233237.79085.57

Kendall-Tackett, K. (2009). Psychological trauma and physical health: A psychoneuroimmunology approach to etiology of negative health effects and possible interventions. Psychological Trauma: Theory, Research, Practice, and Policy, 1(1), 35-48. https://doi.org/10.1037/a0015128

Kroenke, K., \& Spitzer, R. L. (2002). The PHQ-9: A new depression diagnostic and severity measure. Psychiatric Annals, 32(9), 509-515. https://doi.org/10.3928/0048-5713-20020901-06

Ladwig, K.-H., Lederbogen, F., Albus, C., Angermann, C., Borggrefe, M., Fischer, D., ... Jünger, J. (2014). Position paper on the importance of psychosocial factors in cardiology: Update 
2013. GMS German Medical Science, 12, Doc09 . https://doi. org/10.3205/000194

Lanas, F., Avezum, A., Bautista, L. E., Diaz, R., Luna, M., Islam, S., $\&$ Yusuf, S. (2007). Risk factors for acute myocardial infarction in Latin America. Circulation, 115(9), 1067-1074. https://doi. org/10.1161/CIRCULATIONAHA.106.633552

Lane, D., Carroll, D., Ring, C., Beevers, D. G., \& Lip, G. Y. H. (2001). Mortality and quality of life 12 months after myocardial infarction: Effects of depression and anxiety. Psychosomatic Medicine, 63(2), 221-230. https://doi.org/10.1097/00006842200103000-00005

Lee, K. S., Lennie, T. A., Wu, J.-R., Biddle, M. J., \& Moser, D. K. (2014). Depressive symptoms, health-related quality of life, and cardiac event-free survival in patients with heart failure: A mediation analysis. Quality of Life Research, 23(6), 18691876. https://doi.org/10.1007/s11136-014-0636-5

León-Pérez, Wallston, K. A., Goggins, K. M., Poppendeck, H. M., \& Kripalani, S. (2016). Effects of stress, health competence, and social support on depressive symptoms after cardiac hospitalization. Journal of Behavioral Medicine, 39(3), 441452. https://doi.org/10.1007/s10865-015-9702-x

Lichtman, J. H., Bigger, J. T., Blumenthal, J. A., FrasureSmith, N., Kaufmann, P. G., Lespérance, F., ... Froelicher, E. S. (2008). Depression and coronary heart disease. Circulation, 118(17), 1768-1775. https://doi.org/10.1161/ CIRCULATIONAHA.108.190769

Lichtman, J. H., Froelicher, E. S., Blumenthal, J. A., Carney, R. M., Doering, L. V., Frasure-Smith, N., ... Wulsin, L. (2014). Depression as a risk factor for poor prognosis among patients with Acute Coronary Syndrome: Systematic review and recommendations. A scientific statement from the American Heart Association. Circulation, 129(12), 1350-1369. https:// doi.org/10.1161/CIR.0000000000000019

Lugo, L. H., Garcia, H. I., \& Gomez, C. (2006). Confiabilidad del cuestionario de calidad de vida en salud SF-36 en Medellín, Colombia. Revista Facultad Nacional de Salud Pública, 24(2), 37-50

Mendis, S. Puska, P., \& Norrving, B. (2011). Global atlas on cardiovascular disease prevention and control. Geneva, Suiza: WHO Press.

Merz, C. N. B., Dwyer, J., Nordstrom, C. K., Walton, K. G., Salerno, J. W., \& Schneider, R. H. (2002). Psychosocial stress and cardiovascular disease: Pathophysiological links. Behavioral Medicine, 27(4), 141-147. https://doi. org/10.1080/08964280209596039

Muthén, B. O., \& Kaplan, D. (1985a). A comparison of some methodologies for the factor analysis of nonnormal Likert variables. British Journal of Mathematical and Statistical Psychology, 38, 171-189. https://doi. org/10.1111/j.2044-8317.1985.tb00832.x

Muthén, B. O., \& Kaplan, D. (1985b). A comparison of some methodologies for the factor analysis of non-normal Likert variables: A note on the size of the mode. British Journal of Mathematical and Statistical Psychology, 45, 19-30. https:// doi.org/10.1111/j.2044-8317.1992.tb00975.x

Muthén, L. K., \& Muthén, B. O. (2010). Mplus User's Guide: Statistical Analysis with Latent Variables: User'ss Guide. Los Angeles: Muthén \& Muthén.

Nabi, H., Kivimäki, M., Suominen, S., Koskenvuo, M., SinghManoux, A., \& Vahtera, J. (2010). Does depression predict coronary heart disease and cerebrovascular disease equally well? The Health and Social Support Prospective Cohort Study. International Journal of Epidemiology, 39(4), 1016-1024. https://doi.org/10.1093/ije/dyq050

Nascimento, L., Alves, S., Pio, M., \& Carisi, A. (2009). World Health Organization quality of life instrumentbrief and Short Form-36 in patients with coronary artery disease: Do they measure similar quality of life concepts?
Psychology, Health \& Medicine, 14(5), 619-628. https://doi. org/10.1080/13548500903111814

Navarro-García, M. A., Marín-Fernández, B., de Carlos-Alegre, V., Martínez-Oroz, A., Martorell-Gurucharri, A., OrdoñezOrtigosa, E., ... Elizondo-Sotro, A. (2011). Trastornos del ánimo preoperatorios en cirugía cardiaca: factores de riesgo y morbilidad postoperatoria en la unidad de cuidados intensivos. Revista Española de Cardiología, 64(11), 1005-1010. https:// doi.org/10.1016/j.rec.2011.06.009

Palacios, J., Khondoker, M., Mann, A., Tylee, A. \& Hotopf, M. (2018). Depression and anxiety symptom trajectories in coronary heart disease: Associations with measures of disability and impact on 3-year health care costs. Journal of Psychosomatic Research, 104, 1-8. https://doi.org/10.1016/j. jpsychores.2017.10.015

Parakh, K., Thombs, B. D., Fauerbach, J. A., Bush, D. E., \& Ziegelstein, R. C. (2008). Effect of depression on late (8 years) mortality after myocardial infarction. The American Journal of Cardiology, 101(5), 602-606. https://doi.org/10.1016/j. amjcard.2007.10.021

Parker, G. B., Hilton, T. M., Walsh, W. F., Owen, C. A., Heruc, G. A., Olley, A., ... Hadzi-Pavlovic, D. (2008). Timing is everything: The onset of depression and Acute Coronary Syndrome outcome. Biological Psychiatry, 64(8), 660-666. https://doi.org/10.1016/j.biopsych.2008.05.021

Puddu, P. E., Piras, P. \& Menotti, A. (2017). Lifetime competing risks between coronary heart disease mortality and other causes of death during 50 years of follow-up. International Journal of Cardiology, 228, 359-363. https://doi.org/10.1016/j. ijcard.2016.11.157

Romero, E. (2010). Confiabilidad del cuestionario de salud SF-36 en pacientes postinfarto agudo del miocardio procedentes de Cartagena de Indias, Colombia. Revista Colombiana de Cardiología, 17(2), 41-46. https://doi.org/10.1016/S01205633(10)70218-7

Rosengren, A., Hawken, S., Ôunpuu, S., Sliwa, K., Zubaid, M., Almahmeed, W. A., ... Yusuf, S. (2004). Association of psychosocial risk factors with risk of acute myocardial infarction in 11119 cases and 13648 controls from 52 countries (the INTERHEART study): Case-control study. The Lancet, 364(9438), 953-962. https://doi.org/10.1016/S01406736(04)17019-0

Ruo, B., Rumsfeld, J. S., Hlatky, M. A., Liu, H., Browner, W. S., \& Whooley, M. A. (2003). Depressive symptoms and healthrelated quality of life: the Heart and Soul Study. JAMA, 290(2), 215-221. https://doi.org/10.1001/jama.290.2.215.

Scherrer, J. F., Chrusciel, T., Garfield, L. D., Freedland, K. E., Carney, R. M., Hauptman, P. J., ... Lustman, P. J. (2012). Treatment-resistant and insufficiently treated depression and all-cause mortality following myocardial infarction. The British Journal of Psychiatry, 200(2), 137-142. https://doi. org/10.1192/bjp.bp.111.096479

Ski, C. F., Jelinek, M., Jackson, A. C., Murphy, B. M., \& Thompson, D. R. (2015). Psychosocial interventions for patients with coronary heart disease and depression: A systematic review and meta-analysis. Heart, Lung and Circulation, 21, S306. https://doi.org/10.1016/j.hlc.2012.05.756

Ski, C. F., Worrall-Carter, L., Cameron, J., Castle, D. J., Rahman, M. A., \& Thompson, D. R. (2015). Depression screening and referral in cardiac wards: A 12-month patient trajectory. European Journal of Cardiovascular Nursing, 6(12), 157-166. https://doi.org/10.1177/1474515115583617

Spitzer, R. L., Kroenke, K., \& Williams, J. B. W. (1999). Validation and utility of a self-report version of PRIME-MD. JAMA: The Journal of the American Medical Association, 282(18), 17371744. https://doi.org/10.1001/jama.282.18.1737

Thombs, B. D., Bass, E. B., Ford, D. E., Stewart, K. J., Tsilidis, K. K., Patel, U., ... Ziegelstein, R. C. (2006). Prevalence 
of depression in survivors of acute myocardial infarction. Journal of General Internal Medicine, 21(1), 30-38. https:// doi.org/10.1111/j.1525-1497.2005.00269.x

Thombs, B. D., Ziegelstein, R. C., Stewart, D. E., Abbey, S. E., Parakh, K., \& Grace, S. L. (2008). Usefulness of persistent symptoms of depression to predict physical health status 12 months after an acute coronary syndrome. The American Journal of Cardiology, 101(1), 15-19. https://doi.org/10.1016/j.amjcard.2007.07.043

Vilagut, G., Ferrer, M., Rajmil, L., Rebollo, P., Permanyer-Miralda, G., Quintana, J. M., ... Alonso, J. (2005). El cuestionario de salud SF-36 español: Una década de experiencia y nuevos desarrollos. Gaceta Sanitaria, 19(2), 135-150. https://doi. org/10.1157/13074369

Volz, A., Schmid, J.-P., Zwahlen, M., Kohls, S., Saner, H., \& Barth, J. (2011). Predictors of readmission and health related quality of life in patients with chronic heart failure: A comparison of different psychosocial aspects. Journal of Behavioral Medicine, 34(1), 13-22. https://doi.org/10.1007/s10865-010-9282-8

Wang, E. Y., Dixson, J., Schiller, N. B. \& Whooley, M.A. (2017). Causes and predictors of death in patients with Coronary Heart Disease (from the Heart and Soul Study). The American Journal of Cardiology, 119(1), 27-34. https://doi.org/10.1016/j. amjcard.2016.09.006.

Wang, W., Jiang, Y., \& Lee, C. H. (2016). Independent predictors of physical health in community-dwelling patients with coronary heart disease in Singapore. Health and Quality of Life Outcomes, 14(1), 113. https://doi.org/10.1186/s12955-016-0514-7
Wei, J., Rooks, C., Ramadan, R., Shah, A. J., Bremner, J. D., Quyyumi, A. A., ... Vaccarino, V. (2014). Meta-analysis of mental stress-induced myocardial ischemia and subsequent cardiac events in patients with Coronary Artery Disease. The American Journal of Cardiology, 114(2), 187-192. https://doi. org/10.1016/j.amjcard.2014.04.022

White, M. L., \& Groh, C. J. (2007). Depression and quality of life in women after a myocardial infarction. Journal of Cardiovascular Nursing, 22(2), 138-144. https://doi. org/10.1097/00005082-200703000-00012

World Health Organization. (2014). Global status report on noncommunicable diseases 2014. Switzerland: WHO Press.

Williams, L. S., Ghose, S. S., \& Swindle, R. W. (2014). Depression and other mental health diagnoses increase mortality risk after ischemic stroke. American Journal of Psychiatry, 161(6), 10901095. https://doi.org/10.1176/appi.ajp.161.6.1090

Worcester, M. U. C., Murphy, B. M., Elliott, P. C., Grande, M. R., Higgins, R. O., Goble, A. J., \& Roberts, S. B. (2007). Trajectories of recovery of quality of life in women after an acute cardiac event. British Journal of Health Psychology, 12(1), 1-15. https://doi.org/10.1348/135910705X90127

Ziegelstein, R. C., Fauerbach, J. A., Stevens, S. S., Romanelli, J., Richter, D. P., \& Bush, D. E. (2000). Patients with depression are less likely to follow recommendations to reduce cardiac risk during recovery from a myocardial infarction. Archives of Internal Medicine, 160(12), 1818-1823. https://doi. org/10.1001/archinte.160.12.1818. 